\title{
Mechanical properties (Tensile, Hardness and Shock resistance) for the phenol formaldehyde resin with Epoxy resin
}

\author{
Mustafa A. Rajab ', Ekhlas I. Kader ${ }^{2}$, Ali Adwan Hammod ${ }^{2}$, Abdul Hameed I. Hameed ${ }^{2}$, \\ ${ }^{1}$ Mechanical. Department, Technical Institute of Baqubah, Middle Technical University \\ ${ }^{2}$ Department of Mechanical Engineering, College of Engineering, University of Diyala \\ mustafaalnajar677@yahoo.com
}

\begin{abstract}
:
Phenolic formaldehyde (resole) resin was used at a different weight $(10 \%, 20 \%, 30 \%, 40 \%)$, with epoxy resins at varying percentages $(90 \%, 80 \%, 70 \%, 60 \%)$ at $20 \mathrm{C}^{\circ}$. In order to study the mechanical properties (which including: Tensile strength, hardness and shock resistance), for the purpose of analysis and comparison with the mechanical properties of alloys, and the selected part for the purpose of replacing the alloy with the composite materials to reduce weight and improve mechanical properties. The results indicate improved properties with increased epoxy resins due to increased bonding between components.
\end{abstract}

\section{Paper History:}

(Received:1/11/2017; Accepted: 17/1/2018)

\section{1 . Introduction:}

The evolution in technology is depending on advances in the materials field. We need to understand the utility of the design of the most advanced cars or aircraft, and it must provide appropriate materials to ensure loads and service conditions. Whatever the fields are, the materials are the first condition to the advance development[1]. Composite materials are the combination of two or more materials that have one or more various properties. Combining materials for properties of a new compound is used to improve mechanical, physical, thermal, trip logical, electrical, and environmental-friendly properties Fig. (1), [2]. Usually, to realization appointed balance of properties the composite materials are optimized for an appointed group of applications. [3]. Difficult to agree upon a single and simple definition, because there is a range of materials which would be considered as composite materials and the wide range of uses for which may be designed the composite materials[4]. However, the practical common definition may be limited to confirm materials that have a matrix to link the contents together and provides strength and stiffness constituent of reinforcement [4,5]. A lightweight structural composite is an example of a composite material that acquired by putting continuous carbon fibers in one or more orientations in a matrix of the polymer. This fiber gives higher strength and stiffness, while the polymer works as a matrix. The attractive properties of polymer- matrix reinforced with carbon fiber composites as a following [6]:

$\square$ Low density (lower than aluminum)

$\square$ High strength $\square$ High stiffness

$\square$ Good creep resistance

$\square$ Low friction coefficient and good wear resistance

$\square$ Toughness and damage tolerance (as enabled by using appropriate fiber orientations)

$\square$ Chemical resistance (chemical resistance controlled by the polymer matrix)

$\square$ Corrosion resistance

$\square$ Dimensional stability

Polymers became an essential and ubiquitous part of our lives: car parts, aircraft frames, telephones, computers, human body prostheses, and numerous other material goods that we take for granted are composed largely of polymers [7]. And these defects can be solved by reinforcing other materials with polymers. Secondly, the polymer matrix composite does not require processing by high pressure and high temperature. For these rationale polymer matrix composites are developing quickly and soon becoming popular for structural applications. Generally, Polymers are very high molecular mass material. A polymer is formed through the combinations of many smaller units (monomer) by suitable chemical reactions. Polymers, have various structures[8]. The term (linear) is used for polymers in which the carbon atoms are joined together as a continuous sequence in a chain[10]. The polymer structures with groups are generally known as (branched). Polymers also have (cross-linked) structures. They are three dimensional systems[9]. artificial linear, branched and network polymer structures are shown below Fig. (2).

Polymers can be classified to two major groups:

1. Thermoplastic polymers (Thermoplastics).

2. Thermosetting polymers (Thermosets).

Epoxy resins are among the most versatile thermosets. They were first synthesized by Pierre Caston in Switzerland and S. O. Greenlee in the United States late in the 1930s. Figure (3) illustrated the chemical structure of epoxy [10]. Epoxy resins are obtained by condensation polymerization of epichlorohydrin and polyhydroxy compound (e.g. bisphenol) Fig. (4) , [11] . The simplest epoxy resin is prepared by the reaction of bisphenol A with epichlorohydrine, this epoxy resin is also represented by the diglycidyl ether of biphenyl A (DGEBA) as shown in Fig. (5) [12].

Phenol formaldehyde resins

This type of polymer is made from two main substances: phenol and formaldehyde. Phenol is a colorless solid compound, but when exposure to oxidation in the air its 
colored by pink, then brown. It has strong odor and penetrating [13] . It is Limited soluble in water and Little bit acidic, so when transaction with it, is necessary worn the epidermis protective clothing, because exposure to high concentration caused serious burns. Although phenols are manufactured chemicals, they can be found naturally as a result of the degradation of animal and plant residues and other organic matter. Phenol is widely used in the manufacture of materials for plastics, including drinking water bottles, as well as in the clothing industry [14]. Phenol is used in the installation of nylon. It has medical uses, it is used in the manufacture of disinfectants, lotions, ointments, topical anesthetics and the pharmaceutical industry. Formaldehyde is a chemically unsteady organic compound $\left(\mathrm{CH}_{2} \mathrm{O}\right)$, colorless gas that can be melted in water in large quantities [15]. As well as in the production of chemicals and polymers and is often used in the manufacture of coatings and explosives [15]. In general, phenol-formaldehyde produced by two ways, for manufacture two types of polymers, namely Novolac and Resole [16]. Novolac: This type of polymers produced by mixing formaldehyde ( $37 \%$ water solution) with phenol by added an acidic helper (sulfuric, phosphoric or oxalic acid), and heated to the required degree and then equivalent the reaction mixture, and remove the water by distillation (in its final stages under discharge) to a temperature Estimated $160^{\circ}$ C. Novolac resins are chemically converted from thermoplastic polymers to thermoset polymers by added his hardener hexamethylenetetramine (HMTA) [17] . Resole: This type is produced by added basic helper with more formaldehyde relative to phenol. Initially, its consists (Oligomer) is called a resole and it is not needed to a hardener (HMTA) but it need just heat treatment [18].

\section{Experimental Procedure:}

The practical part includes the preparation of the raw materials and how to prepare them in addition to the mechanical tests carried out on the composite material, This as shown in Flow chart for experimental part. These materials were mixed with different weight as shown in Table (1). At first, the substance was mixed with phenol formaldehyde resin, called resole. Material used: The material used in this work divided to two matrix material:

1- Epoxy resin

2- Phenol formaldehyde (resole) resin

Epoxy resin (EP): Epoxy resin used in this work was LEYCO-POX 103 which is a two component, low viscosity epoxy resin (which transforms into solid state after adding the hardener with mixing ratio of $3: 1$ )

Advantages of this product: [6]

- Low viscosity

- Short pot live

- High mechanical strength

- Protects against carbonation

- Weather-resistant
There are several instruments and equipment utilized to measure and determine the mechanical properties of the materials under investigation.

Later, tests will be carried out. Three types of models have been manufactured for mechanical tests.

\section{Results and Discussions}

Mechanical properties were measured at room temperature (20-30) $\mathrm{C}$. Using different types mechanical testing instruments as follows (Fig. 6):

Tensile strength: Tensile characteristics are the most widely reported mechanical properties of any material. Its resistance to tensile strength is very low, but when adding resole, its tensile strength will improve significantly (Fig. 7). The tensile strength of the composite material because it is characterized by its low elasticity. Tensile strength is increased by increasing the added weight ratios as they occupy more space within the resin allowing better load distribution.

Table (2) shows ultimate tensile values, which show the changes in tensile strength depending on the mixing ratio. Hardness: The hardness is the ability of a material to resist penetration, the shore $\mathrm{D}$ hardness values showed that the results of the different mixing ratio. Table (3) and Fig. (8) Show the hardness of the composites blends. As for the hardness properties, the resins are considered to be nonsolid materials, which are low. This is what we see in Fig. (8), but when adding the resole material to it, the hardness characteristic will improve clearly. Hardness of overlapping material. The hardness is increased by increasing the added weight ratios as they occupy more space within the resin allowing better load distribution. Impact strength test: Impact Test Instrument as shown in Fig. (9). Mechanisms of failure occurring in material due to quick stress, the material is ductile under static stress and becomes brittle under dynamic quick stress. Fig. (10) shows the resistance values of the shock with the weight ratios of the mix. The resistance of the shock is generally low for resins because of its thickness. After mixing, the value of the shock resistance increases. This is due to the fact that the mixing materials will bear the bulk of the impact energy exerted on the composite material which improves this resistance. Thus, resistance to trauma increases with increased strength to $40 \%$ and $60 \%$.

\section{Conclusions:}

The results obtained can be summarized as follows: 1Low values of mechanical properties with increasing proportion of phenol formaldehyde (resole) resin.

2- Improve the values of tensile strength and hardness with increasing the proportion of epoxy resin.

3 - The durability values increase with the increase in the added weight of epoxy due to increased bonding between the components.

\section{References:}

[1] P. Vincenzini and M. Singh "Advanced Inorganic Fibrous Composites V ", Trans Tech Publications, 2006. 
[2] Ebewele, Oboigbaotor R, "Polymer Science and Technology", CRC Press, New York, 2000.

[3] Reading, M. 1993. Trends in Polymer Science 1(8): 248-253.

[4] Reading, M., D. Elliot and V.L. Hill. 1993. Journal of Thermal Analysis. 40(3): 949-955.

[5] Jun Zheng , " STUDIES OF PF RESOLE ISOCYANATE HYBRID ADHESIVES ", Ph. D, Thesis, Virginia Polytechnic Institute and State University, 2008.

[6] ASTM, “Annual Book of ASTM Standard", Section 8, Plastics (I). Vol. (08-01), Easton, M. V. S. A., 1989.

[7] Crawford, R. J., "Plastic Engineering", 2nd Edition, Pergamon Press USA, 1987.

[8] P.K. Mallick "Fiber-Reinforced Composites: Materials, Manufacturing, and Design", 3rd Edition , CRC Press, 2007.

[9] E.P.DeGarmo, J.T. Black, and R.A. kohser " Materials and processes in Manufacturing ", 10th Edition, john Wiley \& Sons , 2008 .

[10] Liyong Tong ,Adrian P.Mouritz ,Michael K.Bannister "3D Fiber Reinforced Polymer Composites" , First Edition, Elsevier Science Ltd , 2002 .

[11] Halem, Ali Hoby,1999 " Improvement Properties of Reinforced Plastic Materials ", MSC Thesis , Engineering College, Babylon University, Iraq.

[12] Incropera F.P and DeWitt D.P., Introduction to Heat Transfer, 3rd Edition, John Wiley \&Sons , 1996.
[13] B.A.Azhdar "Impact Fracture Toughness of Fiber Reinforced Epoxy Resin” ,M.SC Thesis ,U.O.T ,1992

[14] Ali I.Al-Mosawi "Study of Some Mechanical Properties for Polymeric Composite Material Reinforced by Fibers ", Al-Qadessiyah Journal For Engineering Science, Vol 2, No 1, 2009 . pp.14-24

[15] Dr. Abbas A. Al-Jeebory, Ali I.Al-Mosawi, Sajed A. Abdul Allah "Effect of percentage of Fibers Reinforcement on Thermal and Mechanical Properties for Polymeric Composite Material ", Iraqi Journal of Mechanical and Materials Engineering , First Conference of Engineering College , 2009

[16] Bogomolov V. and Kartenko N. "Thermal Conductivity of the Opal- Epoxy Resin Nanocomposite ", Physics of the Solid State, Vol 45,No 5,PP.957-960, 2003.

[17] F.Rondeaux , ph. Bredy and J.M.Rey. "Thermal Conductivity Measurements of Epoxy Systems at Low Temperature" , Cryogenic Engineering Conference (CEC), USA, July 16-20, 2001

[18] Dr. Kahtan K.Al-Khazraji , Ali I.Al-Mosawi "Study of Thermal Behavior for Composite Material Consisted from Unsaturated Polyester Resin Reinforced by Palms and Glass Fibers" , Journal of Babylon University, Engineering Sciences, Vol 9 , No 5 , pp.867 - 876, 2004.

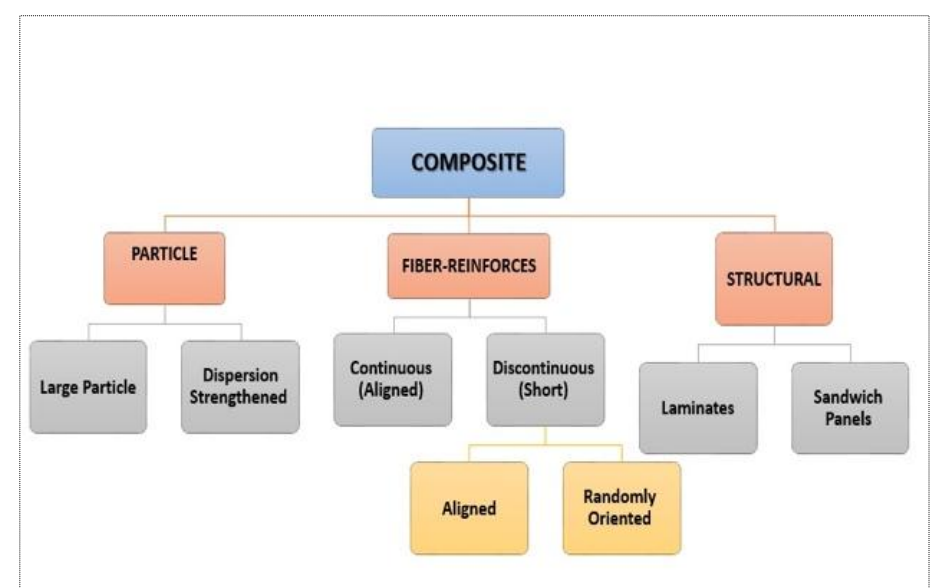

Figure. (1): A classification scheme for the various composite types [1] 


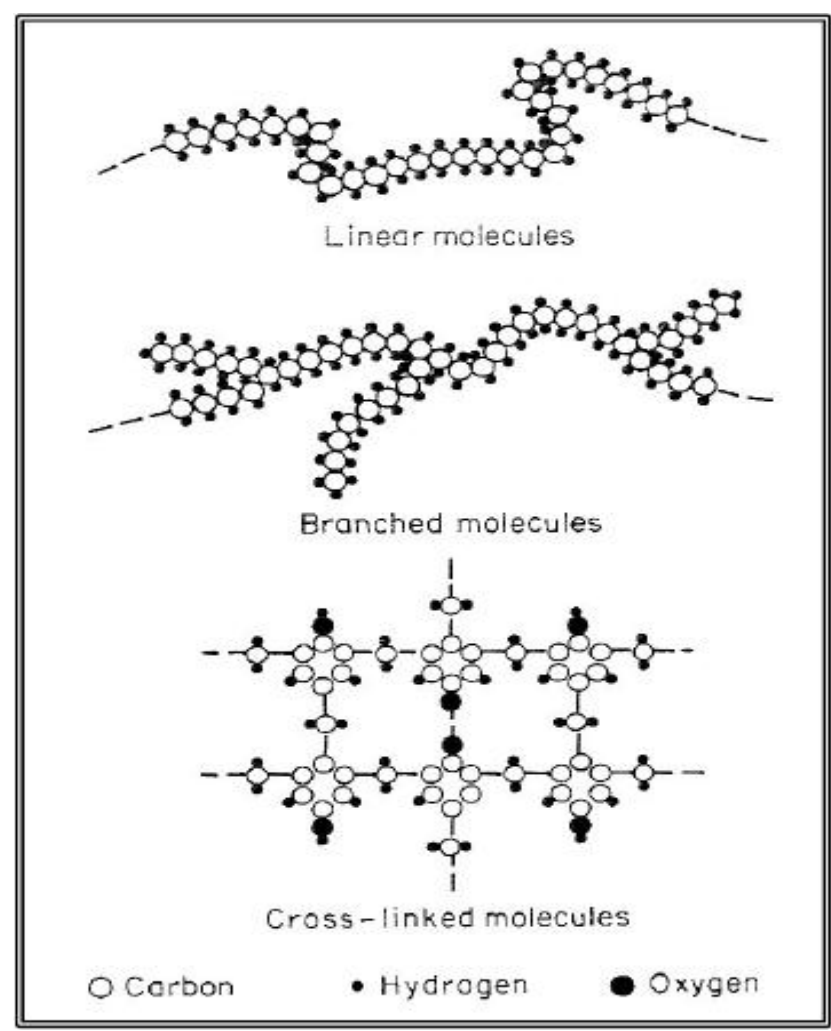

Fig. (2) Polymer Chains: (A) Linear, (B) Branched, (C) Cross-Linked, Structures[12].

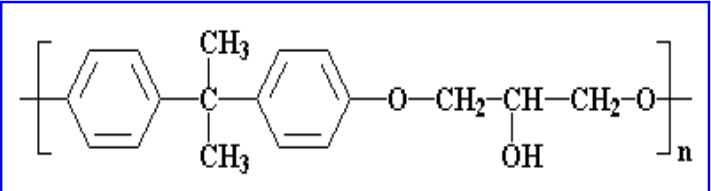

Fig.(3) structural unite of (EP) [4].

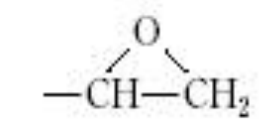

Fig. (4): Epoxide group [3].

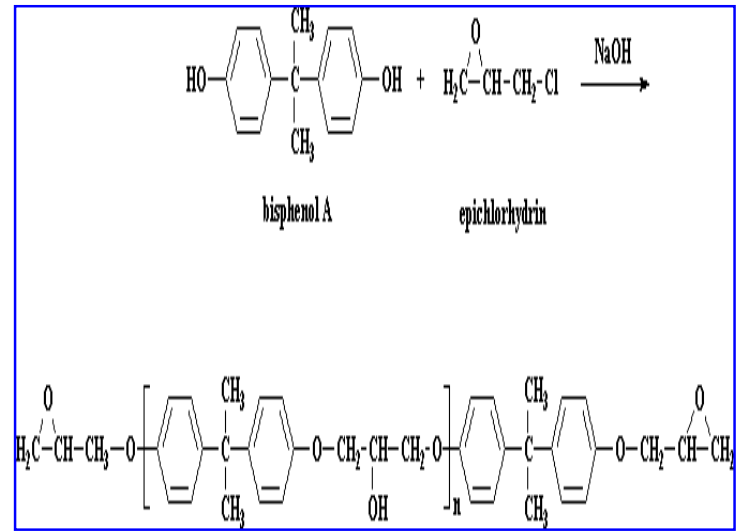

Fig. (5): (DGEBA) epoxy resin equation preparation [4]. 
Table (1)

\begin{tabular}{|c|c|}
\hline Technical Data & \\
\hline Density & $1,05 \mathrm{~g} / \mathrm{cm}^{3}\left(\right.$ at $\left.23{ }^{\circ} \mathrm{C}\right)$ \\
\hline $\begin{array}{c}\text { Minimum curing } \\
\text { temp }\end{array}$ & $2-10{ }^{\circ} \mathrm{C}$ \\
\hline Fully cured & 7 days $\left(23^{\circ} \mathrm{C}\right)$ \\
\hline Linear shrinkage & $0,3 \%$ \\
\hline Volume shrinkage & $3,5 \%$ \\
\hline Compr. strength & $85-100 \mathrm{~N} / \mathrm{mm}^{2}$ \\
\hline Modulus of elasticity & 2800 \\
\hline Viscosity DIN 4 mm & $75-91 \mathrm{sec}$ \\
\hline
\end{tabular}

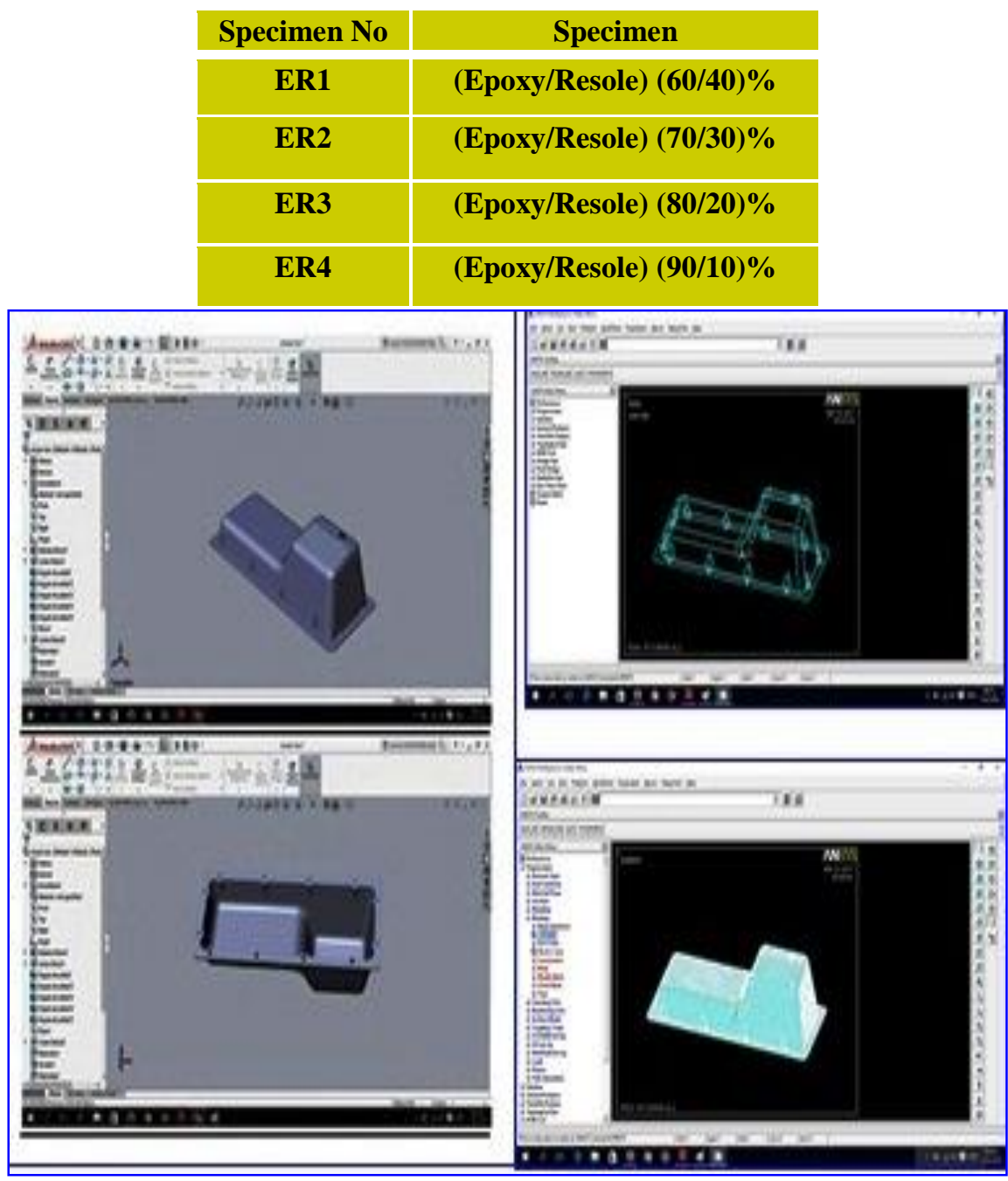

Figure shows the oil basin model

(Oil Pin) in the car engine, as a model for comparison in the simulation program used 
Table (2) Ultimate Tensile Strength of the Composites Blends

\begin{tabular}{|c|c|}
\hline Sample No. & $\begin{array}{c}\text { Ultimate Tensile Strength } \\
\text { (UTS) (Mpa) }\end{array}$ \\
\hline ER1 & 12.5 \\
\hline ER2 & 26.83 \\
\hline ER3 & 38.35 \\
\hline ER4 & 47.3 \\
\hline
\end{tabular}

Table (3) Shore D Hardness of the composites blends.

\begin{tabular}{|c|c|}
\hline Sample No. & Hardness (Shore D) \\
\hline ER1 & 67.8 \\
\hline ER2 & 71.9 \\
\hline ER3 & 75.6 \\
\hline ER4 & 81.2 \\
\hline
\end{tabular}

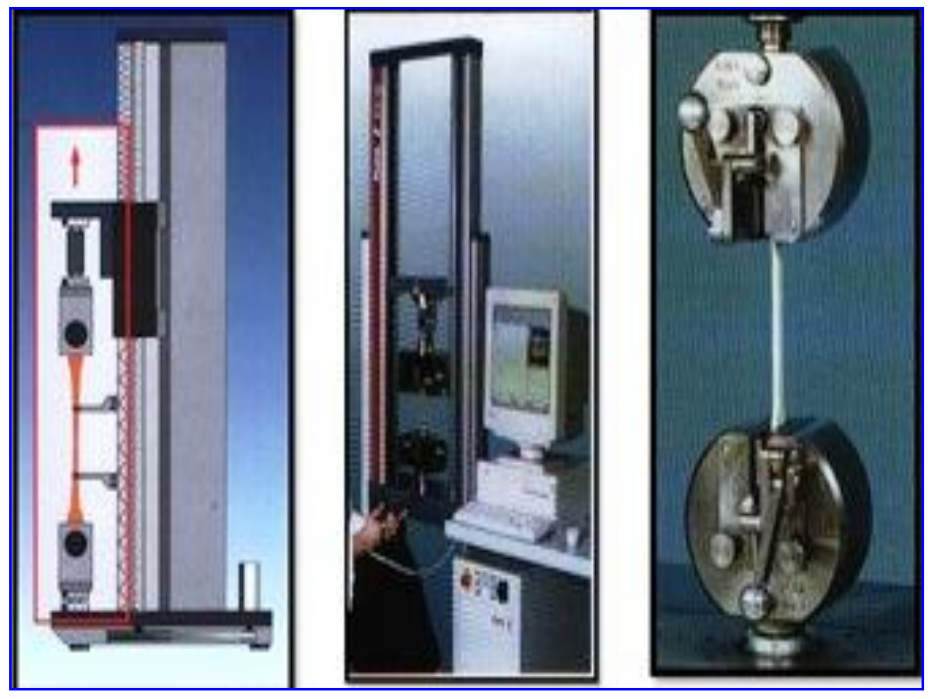

Fig. (6) Tensile Test Instrument 


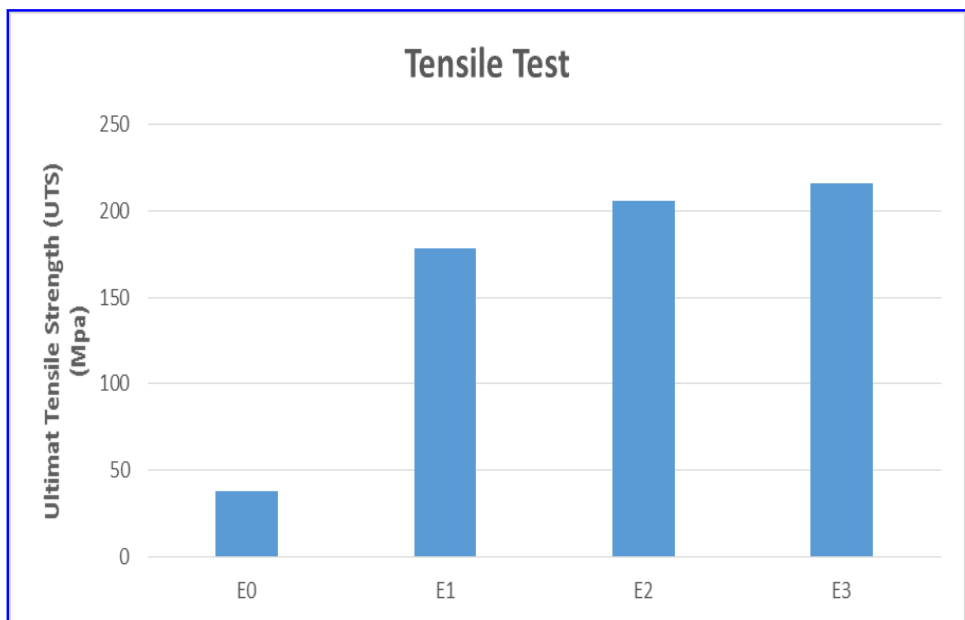

Fig. (7) The Ultimate Tensile Strength of the Composites Blends.

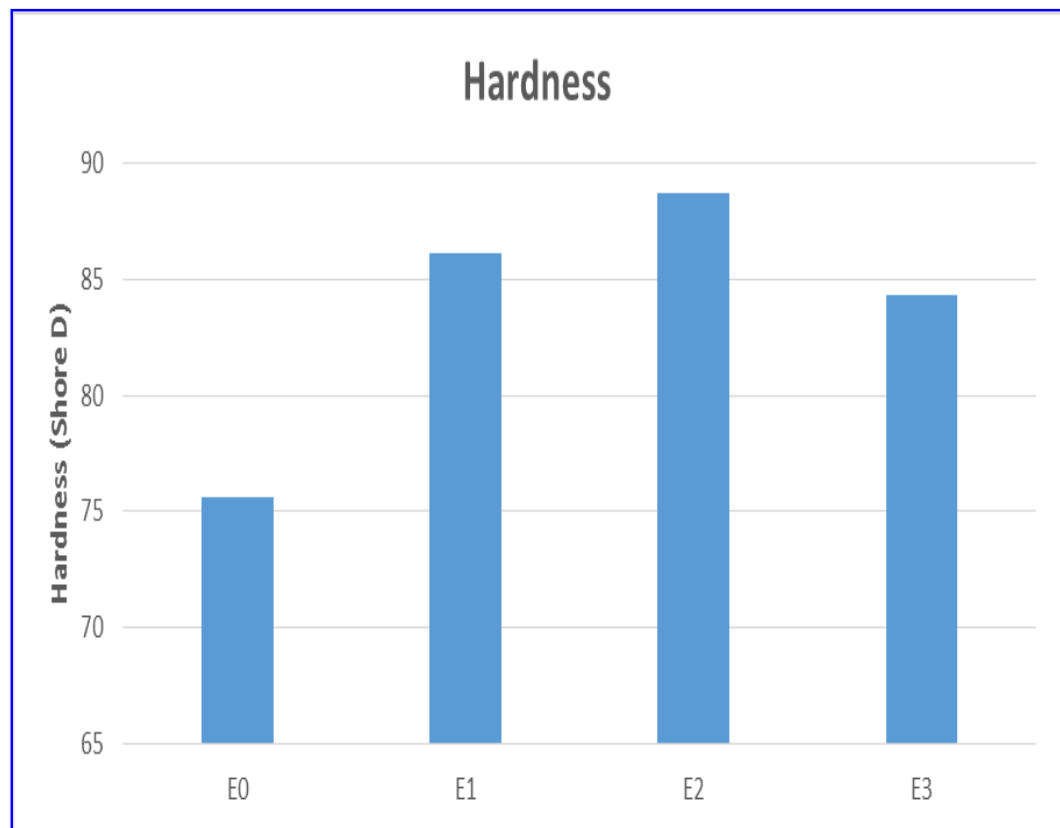

Fig. (8) The Hardness of the Composites Blends 


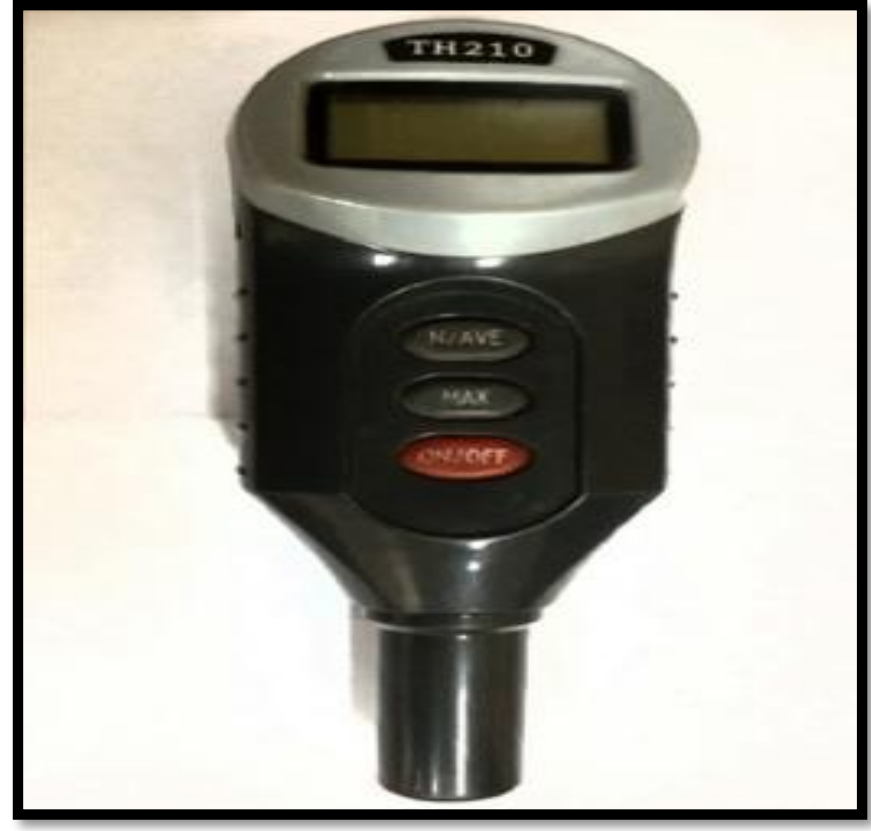

Hardness Test Instrument

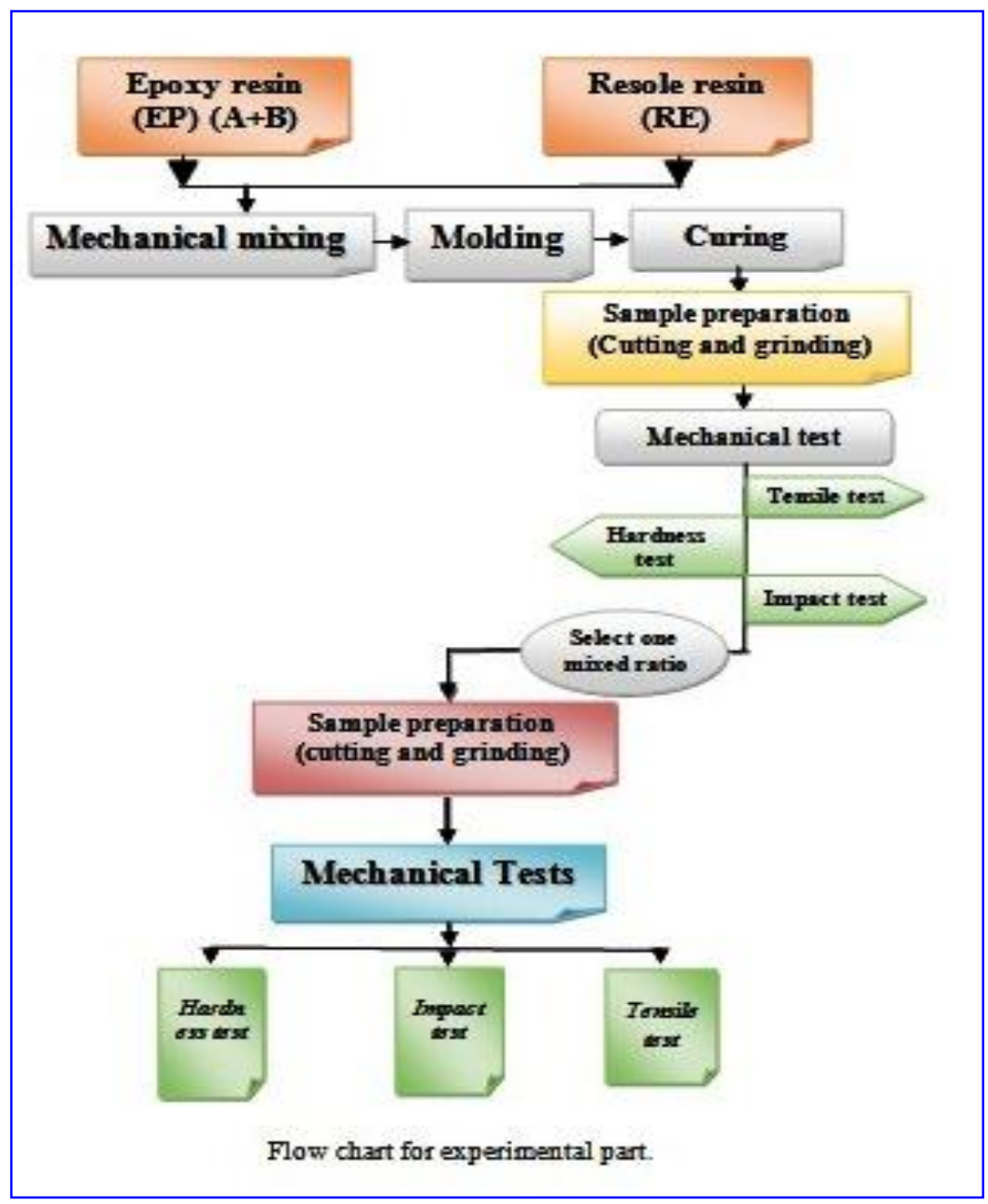



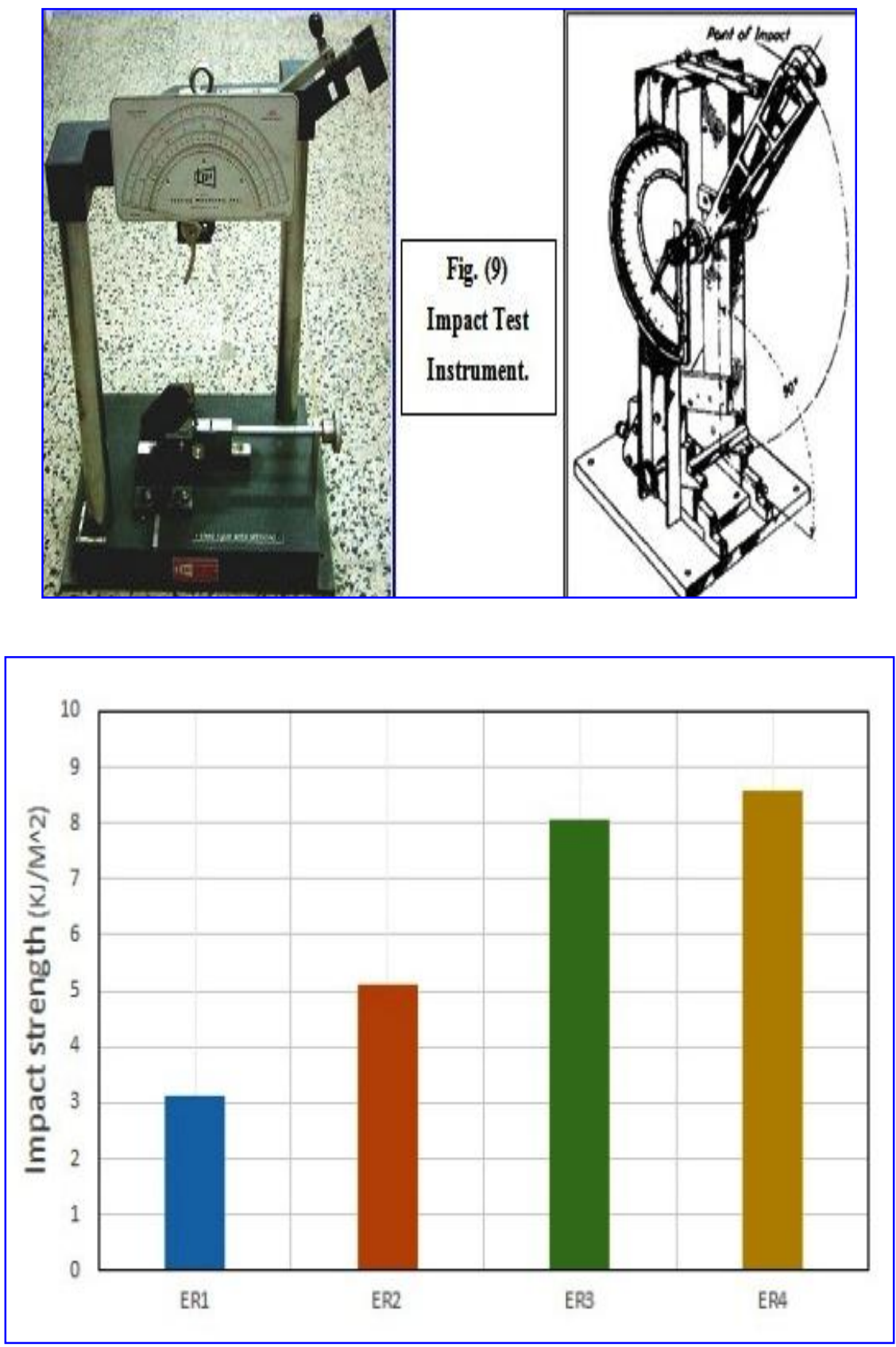

Fig. (10) The Impact of the Composites Blends. 